DOI: $10.47456 / k r k r . v 1 i 4.31824$

\title{
Agroecologia: estratégia de luta para fortalecimento e resistência da Juventude Camponesa
}

Agroecology: strategy to fight for the strengthening and resistance of the Peasant Youth

Lílian Souza Conceição Santos Rosineide Pereira Mubarack Garcia

\begin{abstract}
Resumo: Diante dos dois projetos que se apresentam em disputa no campo brasileiro, Agroecologia e Agronegócio é imprescindível a formação dos jovens camponeses nessa importante categoria teórica, a Agroecologia. Este segmento que tem se mostrado cada vez mais importante na continuidade da luta dos trabalhadores do campo, na permanência do território camponês e na garantia da soberania alimentar. Neste contexto, este artigo tem como objetivo colocar em evidência a necessidade e a importância da formação da Juventude Camponesa em Agroecologia, um projeto da classe trabalhadora, que se constitui em um importante alicerce para a construção da agricultura camponesa capaz de confrontar o agronegócio, que tem gerado a destruição do território camponês. A construção desse debate se deu dentro de uma abordagem qualitativa, utilizando-se da pesquisa teórica. Para fazer essa discussão escolhemos dialogar com os principais teóricos que discutem a Educação do Campo, Agroecologia e Juventude. Dessa forma, a pesquisa aportou seu debate teórico a partir de Caldart (2017), Molina (2014), Freire (2011), Primavesi (2002), Altieri (2012), Caporal (2000), Castro (2009), Weisheimer (2013), dentre outros. A Agroecologia se apresentou de forma imprescindível na construção de um novo projeto para o campo brasileiro, onde se pretende a superação desse modelo econômico e agrícola que promove a insustentabilidade da vida no campo. E a juventude é indispensável nessa construção, diante da constante ameaça deste território pelo avanço do agronegócio demandando cada vez mais terra para produção de produção de mercadoria e não de alimento.
\end{abstract}

Palavras-chave: Agroecologia; Educação do Campo; Juventude e Trabalho.

Abstract: In view of the two projects that are in dispute in the Brazilian field, Agroecology and Agribusiness, it is essential to train young peasants in this important theoretical category, Agroecology. This segment, which has shown itself to be increasingly important in the continuity of the struggle of rural workers, in the permanence of peasant territory and in guaranteeing food sovereignty. In this context, this article aims to highlight the need and the importance of the formation of Peasant Youth in Agroecology, a project of the working class, which constitutes an important foundation for the construction of peasant agriculture capable of confronting agribusiness, which has led to the destruction of peasant territory. The construction of this debate took place within a qualitative approach, using theoretical research. To make this discussion we chose to dialogue with the main theorists who discuss Rural Education, Agroecology and Youth. Thus, the research brought its theoretical debate from Caldart (2017), Molina (2014), Freire (2011), Primavesi (2002), Altieri (2012), Caporal (2000), Castro (2009), Weisheimer (2013), among others. Agroecology was essential in the construction of a new project for the Brazilian countryside, where the intention is to overcome this economic and agricultural model that promotes the unsustainability of rural life. And youth is indispensable in this construction, in view of the constant threat of this territory 
due to the advance of agribusiness, demanding more and more land for the production of production of merchandise and not of food.

Keywords: Agroecology; Rural Education; Youth and Work.

\section{Introdução}

O modelo atual de agricultura industrial capitalista, representada pelos princípios do agronegócio, entende o alimento como mercadoria e a agricultura como negócio, promovendo desenraizamento dos camponeses de seus lugares, a promoção do esvaziamento do campo e a degradação social e ambiental. Assim, estamos caminhando para a destruição do campo, com o fechamento de escolas e o avanço do agronegócio sobre os territórios dos povos tradicionais e camponeses. Neste cenário, é necessário fazer o debate destas questões e pensarmos coletivamente na construção de um projeto de campo que fortaleça e contribua na resistência camponesa, fazendo a denúncia a esse modelo de produção, que tem gerado a destruição do campo brasileiro.

Frente a esse modelo dominante e hegemônico de agricultura, que se mostra insustentável tanto no aspecto social, como ambiental e humanitário, a Agroecologia traz um conceito de projeto social de desenvolvimento baseado na sustentabilidade ecológica e na equidade social, além das outras dimensões do desenvolvimento. E assim, traz importantes contribuições nessa disputa por um projeto de desenvolvimento para o campo.

Não obstante, a classe trabalhadora precisa se engajar na discussão e construção de um projeto coletivo para o futuro do campo baseado em duas importantes categorias que fundamentam a nossa luta, a Educação do Campo e a Agroecologia, estas que são importantes ferramentas de resistência e fortalecimento dos camponeses e camponesas no seu direito de continuar existindo enquanto camponeses. Buscando, assim, o fortalecimento de uma agricultura de base familiar, alicerçada no modo de produzir camponês.

Diante da necessidade de enfrentamento da crise socioambiental constituída no campo brasileiro provocada por um modelo de desenvolvimento capitalista explorador e socialmente excludente, a Agroecologia se constitui em um importante processo auxiliar na formação de coletivos capazes de estabelecer uma nova ordem nas relações sociais e do ser humano com a 
natureza. Sendo assim, é necessário pensar, discutir e inserir nas escolas do campo e nos espaços não escolares de formação, propostas para uma nova dinâmica de desenvolvimento para o campo, um desenvolvimento que respeite o espaço de reprodução ampliada da vida. Assim, a Agroecologia é importante na formação da juventude camponesa, atendendo a demanda deste povo por uma educação humanista e emancipatória, que os contemple em sua necessidade de ter um campo mais justo e ecologicamente viável. E a materialização dessa abordagem nas escolas irá contribuir para o entendimento e enfrentamento político da questão diante da "potencialidade, importância política, ética e formativa de avançar na aproximação entre escolas do campo e agroecologia" (CALDART, 2016, p.1).

Neste contexto, este artigo tem como objetivo colocar em evidência a necessidade e a importância da formação da Juventude Camponesa em Agroecologia, apresentando-a enquanto estratégia de luta para fortalecimento e resistência dessa juventude. Esta categoria que se constitui em um importante alicerce para a construção da agricultura camponesa capaz de confrontar o agronegócio, que tem gerado a destruição do território camponês.

A construção desse debate sobre a necessidade e importância da formação em Agroecologia para a Juventude Camponesa seguiu uma abordagem qualitativa. Para Ludke (1986) esta atitude de pesquisa dá conta de responder às questões propostas pelos atuais desafios da pesquisa educacional.

Nesta abordagem a realidade, enquanto construção social, para ser compreendida precisa ser analisada a partir de diversos aspectos que a compreendem e se relacionam em um determinado contexto.

[...] para os "qualitativos" a realidade é uma construção social da qual o investigador participa e, portanto, os fenômenos só podem ser compreendidos dentro de uma perspectiva holística, que leve em consideração os componentes de uma dada situação em suas interações e influências recíprocas, o que exclui a possibilidade de se identificar relações lineares de causa e efeito e de se fazer generalizações de tipo estatístico (ALVES, 1991, p.55).

Nesta perspectiva metodológica de compreender a realidade e reafirmar o projeto de transformação da sociedade, proposta pela classe trabalhadora, a 
Agroecologia e a Educação do Campo, se fazem importantes instrumentos na formação dos coletivos para que se engajem na luta e na construção desse projeto.

\section{Educação do Campo e Agroecologia}

A Educação do Campo e a Agroecologia são categorias teóricas fundantes para se pensar o campo brasileiro a partir do projeto de campo da classe trabalhadora. Estas propõem muito mais que uma discussão técnicacientífica, mas buscam a superação de um projeto histórico da lógica capitalista hegemônica de organização da agricultura a partir do agronegócio, baseado na monocultura, na utilização de agrotóxicos, na concentração de terras, na produção de commodities agrícolas para exportação, na busca incessante pelo lucro, na padronização da natureza e na exploração à exaustão do trabalho humano e dos recursos naturais, produzindo a degradação ambiental, social e humana no campo.

Enquanto o capitalismo agrário impõe uma relação devastadora sobre o campo, a Agroecologia recupera os saberes produzidos ao longo da história da humanidade no cuidado com a terra. Tendo como centralidade a vida, fundamentada na agricultura camponesa, na socialização da propriedade da terra, na diversidade cultural, na preservação dos recursos naturais que servem de base à reprodução econômica e social dos camponeses, na produção de alimentos saudáveis, em sistemas de produção diversificados, na valorização do saber popular e articulação deste com o conhecimento científico, no estabelecimento de novas relações no campo que sejam socialmente justas, economicamente viável e culturalmente autêntica.

Assim, existem dois projetos que estão em disputa no campo brasileiro e nesse contexto de disputa, a classe trabalhadora levanta suas bandeiras de lutas, a Educação do Campo e a Agroecologia, para fazer luta e resistência a esse modelo de agricultura que tem gerado a destruição do território camponês. $\mathrm{Na}$ construção do Projeto popular, a Agroecologia é o caminho tomado pela classe trabalhadora para a construção da agricultura camponesa capaz de confrontar o agronegócio. 
A agroecologia, como parte do projeto de classe dos trabalhadores, não existe sem os camponeses; estes, por sua vez, precisam de formação política e agroecológica para avançar em seu modo próprio de fazer agricultura. Por isso a educação das novas gerações, na escola e fora dela, é imprescindível ao avanço da agroecologia e das forças produtivas da agricultura, na direção de um desenvolvimento humano igualitário e efetivamente sustentável (CALDART, 2017, p.9).

Fica demonstrado assim, que não se faz Educação do Campo sem Agroecologia, pois é um mecanismo de transformação do campo, o pilar da educação que defendemos e estas são estratégias essenciais na luta e resistência dos camponeses para manter o seu modo de vida, os seus saberes e a sua existência social a partir do seu trabalho na terra.

A Educação do Campo é um movimento que surgiu no Brasil no ano de 1998, e é resultado da luta dos trabalhadores rurais e suas organizações, pelo direito a terra, a educação e de existir enquanto camponeses. Esse movimento nasce para reivindicar uma educação que os contemple em seus espaços, modo de viver e produzir, que valorize seus saberes, seja colocada a partir do seu lugar, que incorpore as suas lutas e que pensa a educação como parte essencial para o desenvolvimento do Campo.

Não basta ter escolas no campo; queremos ajudar a construir escolas do campo, ou seja, escolas com um projeto políticopedagógico vinculado às causas, aos desafios, aos sonhos, à história e à cultura do povo trabalhador do campo (FERNANDES et al., 2011, p. 27).

O histórico de violência contra a população do campo é assustador, uma história de negação de direitos básicos a sua sobrevivência. Em relação a educação no último censo do IBGE (2010), os dados apontam uma triste realidade no campo brasileiro: $15,5 \%$ dos produtores disseram nunca ter frequentado uma escola, $29,7 \%$ não passaram do nível de alfabetização e $79,1 \%$ não foram além do nível fundamental e 23,05\% declararam não saber ler e escrever. A esses povos têm sido negados um direito fundamental para o seu desenvolvimento pleno, a educação, este que garante um melhor exercício de cidadania e participação crítica na sociedade a partir da formação humana integral. 
Caldart (2011), coloca o acesso à educação e a permanência no campo do direito e, por isso esta deve servir a formação de sujeitos de direitos, que a partir de uma formação humana, crítica e emancipatória faça uma leitura crítica e reflexiva da sua realidade buscando intervir sobre ela.

Para Arroyo (2011), o projeto de educação deve ser construído com os próprios sujeitos dos direitos que a exigem, reconhecendo o povo do campo enquanto sujeitos das ações para que se vejam e se construam como também sujeitos de sua educação. Neste sentido, Caldart (2011) afirma que um dos traços fundamentais da Educação do Campo é a luta dos povos do campo por políticas públicas que garanta o direito de todos à educação.

O campo para a Educação do Campo é muito mais do que um espaço geográfico, ele é território, como base material da vida, onde os sujeitos constroem sua identidade, sua cultura e suas relações sociais, por isso é território.

O território é um trunfo dos povos do campo e da floresta. Trabalhar na terra, tirar da terra a sua existência, exige conhecimentos que são construídos nas experiências cotidianas e na escola. Ter o seu território implica em um modo de pensar a realidade (FERNANDES \& MOLINA, 2005, p.8).

Diferente do agronegócio que compreende o campo simplesmente como espaço de produção de mercadorias. Assim os sujeitos do campo constroem um jeito próprio de agir e pensar sobre a sua realidade, produzindo seus próprios espaços, instituindo a educação como uma das dimensões fundamentais na constituição desse território, assim sendo, é possível observar no campo, as formas distintas como os territórios do campesinato e do agronegócio se organizam:

Um exemplo importante é que enquanto o agronegócio organiza o seu território para a produção de mercadorias, dando ênfase a esta dimensão territorial, o campesinato organiza o seu território para realização de sua existência, necessitando desenvolver todas as dimensões territoriais. Esta diferença se expressa na paisagem e pode ser observada nas diferentes formas de organizações de seus territórios (FERNANDES, 2006, p.29).

Enquanto o agronegócio considera apenas uma dimensão do seu território, a dimensão econômica, tornando o seu território homogêneo, com as 
monoculturas e com pouca gente diante da área transformada em mercadoria, marca do território do agronegócio, o território camponês é marcado pela diversidade na paisagem caracterizada pela maior presença de pessoas que constroem suas existências, onde (re)produzem sua cultura e produzem seus alimentos.

A Educação do Campo nasce da crítica e da tomada de posição da população que vive no campo em relação à realidade educacional desse meio. Lutando por políticas públicas que garantam o direito dos povos do campo a uma educação que seja no e do campo: "No: o povo tem direito a ser educado no lugar onde vive; Do: o povo tem direito a uma educação pensada desde o seu lugar e com a sua participação, vinculada à sua cultura e às suas necessidades humanas e sociais" (CALDART, 2011, p. 149).

Assim, essa nova proposta de educação se alicerça nas práticas sociais dessas populações, nos seus conhecimentos, habilidades, sentimentos, valores, modo de ser e produzir, e de se relacionar com a terra.

Por Educação do Campo concebe-se toda a ação educativa que
incorpora espaços da floresta, da pecuária, das minas e da
agricultura, mas os ultrapassa ao acolher a si os espaços
pesqueiros, caiçaras, ribeirinhos, pantaneiros e extrativistas
(SILVA, 2004, p.6).

Os sujeitos da Educação do Campo são os camponeses, negros, indígenas, quilombolas, sujeitos de resistência, e esta educação se faz atrelada as suas lutas, as lutas sociais do campo, as lutas por um novo projeto de campo onde a produção agrícola esteja atrelada ao respeito à vida no campo. Não podemos falar da educação desses povos sem considerar as condições materiais de sua existência, sem fazer uma leitura dessa realidade e sem promover a organização do povo para que se engaje na luta pela conquista de direitos. Sujeitos que resistem a um processo violento de expatriação, negação de sua história, destruição de sua cultura e suas memórias coletivas.

Digo que os coletivos caiçaras, caboclos, camponeses e índios são índios (e não $33 \%$ índios) no sentido de que são o produto de uma história, uma história que é a história de um trabalho sistemático de destruição cultural, de sujeição política, de " exclusão social" (ou pior, de "inclusão social"), trabalho esse que é propriamente interminável (CASTRO, 2001, p.11). 
Povos que lutam pelo direito de ser e existir no seu lugar, diante de uma demanda cada vez mais crescente por terras para produção de commodities e retira dos povos originários, comunidades tradicionais e camponeses mais do que terra, roubam deles o seu território, o seu espaço de vida. "O enfrentamento dessa nova agroestratégia deve ser pautada por visões que não restrinjam à terra a sua dimensão econômica produtiva, mas a tomem como território, espaço de ser e existir" (SAUER, 2013, p.10).

O projeto de Educação do Campo traz uma reflexão pedagógica que vê o campo como lugar que produz formação através das relações que o homem e a mulher constroem entre eles e com a terra para promover sua existência.

\begin{abstract}
É um projeto de educação que reafirma, como grande finalidade da ação educativa, ajudar no desenvolvimento mais pleno do ser humano, na sua humanização e inserção crítica na dinâmica da sociedade de que faz parte; que compreende que os sujeitos se humanizam ou se desumanizam sob condições materiais e relações sociais determinadas; que nos mesmos processos em que produzimos a nossa existência nos produzimos como seres humanos; que as práticas sociais e, entre elas, especialmente as relações de trabalho conformam (formam ou deformam) os sujeitos (CALDART, 2011, p.154).
\end{abstract}

A Educação do Campo tem o trabalho como princípio educativo. É através do trabalho que o sujeito se constrói como pessoa, ao mesmo tempo em que constrói a sociedade e transforma a realidade em que vive. Para Pistrak (2011) o trabalho é entendido como produção material e cultural da existência humana, é através dele que o homem transforma a natureza para poder sobreviver e criar cada vez mais.

A identidade da Educação do campo é definida pelos seus sujeitos sociais e deve estar vinculada a uma cultura que se produz por meio de relações mediadas pelo trabalho. Assim, o trabalho apresenta outras dimensões, é visto como produção do conhecimento, e este deve ser utilizado para a formação. "Há uma intrínseca e inegável relação entre a educação e a produção material da vida que compreende os processos formativos como constituídos no âmbito das relações sociais, determinadas essencialmente pelo trabalho" (MOLINA, 2010, p.131). Pistrak (2011) afirma que a formação humana não está descolada do real, e propõe uma escola com base no trabalho como meio de formação, 
focados na formação de um novo homem através da construção de uma nova realidade social.

Nessa perspectiva de educação, a produção do conhecimento se dá a partir do contexto cultural e político dos seus sujeitos, assim o conhecimento tem origem nas experiências sociais, dialogando desta maneira com a Pedagogia do Oprimido de Paulo Freire. Na medida em que, através de suas lutas constroem outra sociedade, outro campo e outra história esses sujeitos se constroem, sendo assim os próprios oprimidos sujeitos desta educação, que se formam, conscientizam-se e libertam-se. "Assim, como o opressor, para oprimir, precisa de uma teoria da ação opressora, os oprimidos, para se libertarem, igualmente necessitam de uma teoria de sua ação" (FREIRE, 2011, p.252).

A Educação do Campo tem seu fundamento na prática educativa que se tem desenvolvido nos movimentos sociais. O movimento educa e seus sujeitos são formados através das lutas empreendidas pelos movimentos através da intencionalidade formativa produzida na dinâmica de uma luta social e da organização coletiva que pode ser entendida como um processo formativo:

A Pedagogia do Movimento afirma os movimentos sociais como
um lugar, ou um modo específico, de formação de sujeitos
sociais coletivos que pode ser compreendida como um processo
intensivo e historicamente determinado de formação humana
(CALDART, 2012, p.546).

Esse processo de formação humana acontece através da ação e reflexão sobre a realidade para transformá-la e à medida que transforma o mundo se forma transformando-se.

A Pedagogia Socialista também contribui com o arcabouço teórico da Educação do Campo, esta pedagogia vinculada às experiências de luta social e política, define diferentes concepções de formação humana frente à concepção proposta pelo capital.

A educação do campo se fundamenta nos princípios da pedagogia socialista - formação humana integral, emancipatória, vinculada a um projeto histórico que busque superar a sociedade de classes - e a uma teoria do conhecimento, que o concebe como imprescindível e voltado para a transformação social (SANTOS et. al., 2010, p.53). 
A proposta de Educação do Campo está fortemente vinculada a um novo modelo de desenvolvimento para o campo, um desenvolvimento social, economicamente justo e ecologicamente sustentável:

A necessidade de mudança do paradigma da educação rural para o da educação do campo se dá não só pela análise crítica da escola rural como também das propostas desenvolvimentistas para o campo, em geral centradas no agronegócio e na exploração indiscriminada dos recursos naturais (BRASIL. MEC, 2007, p.13).

No Decreto de $\mathrm{N}^{\circ}$ 7.352, de 4 de novembro de 2010 que dispõe sobre a política de educação do campo, o artigo $2^{\circ}$ trata dos princípios da educação do campo, e entre os princípios no item do II está o desenvolvimento social, economicamente justo e ambientalmente sustentável como um dos princípios:

II- Incentivo à formulação de projetos políticos-pedagógicos específicos para as escolas do campo, estimulando 0 desenvolvimento das unidades escolares como espaços públicos de investigação e articulação de experiências e estudos direcionados para o desenvolvimento social, economicamente justo e ambientalmente sustentável, em articulação com o mundo do trabalho ( $2^{\circ}$ artigo do Decreto de $N^{\circ} 7.352$, de 4 de novembro de 2010).

Assim, a Agroecologia é fundamental dentro da proposta da Educação do Campo, atendendo ao seu princípio de um desenvolvimento que gere vida no campo através de um trabalho digno e emancipado. A escola do campo tem um papel muito importante no desenvolvimento das comunidades onde estão inseridas, por isso se faz necessário o ensino e discussões de temáticas direcionados ao desenvolvimento da comunidade nos aspectos sociais, econômico e ambientalmente sustentável.

Os sujeitos do campo precisam ser contemplados no currículo da escola do campo. O currículo na Educação do Campo deve estar voltado aos interesses da vida no campo, os sujeitos que habitam esse espaço, o seu modo de vida e seus contextos de luta, que valorize seus saberes, sua relação com a terra, valores locais e sua cultura. Para Arroyo (2011), o currículo deve ser construído articulado com os anseios, com as necessidades e interesses dos estudantes $\mathrm{e}$ com a realidade social. Os estudantes têm o direito a "saber-se", saber-se enquanto sujeito do campo, saber de si mesmo, da história de luta e resistência 
do seu povo, das questões do campo, da história do campo brasileiro: "passarão anos na educação fundamental, complementarão a educação média e sairão sem saber nada ou pouco de si mesmos" (ARROYO, 2011, p. 262). A escola do campo precisa ter um currículo adequado aos saberes e às necessidades dos estudantes, que privilegie a permanência dos estudantes no ambiente rural e voltado à Agroecologia como matriz tecnológica para o campo.

E assim este currículo reivindicado por esta educação deve priorizar as questões da vida dos sujeitos, as problemáticas e as potencialidades do contexto local, de modo que suas peculiaridades sejam reconhecidas, respeitadas e levadas em consideração. Buscando atender a um currículo específico no qual o estudante se reconheça e procure compreender a si e ao seu próprio ambiente, dando assim sentido aos saberes aprendidos.

Arroyo (2011), traz o currículo como território em disputa. E quem disputa vez no currículo são os sujeitos da educação do campo, estes exigem ser reconhecidos como sujeitos de experiências sociais e de saberes que requerem ter vez no território dos currículos. Assim esses sujeitos têm pressionado o currículo oficial para incorporar o resultado de suas lutas e não aceitam mais esse currículo empobrecido que tem sido oferecido com a negação de sua história, experiências e lutas.

Através de um currículo voltado ao interesse dos povos do campo e suas especificidades, a escola do campo tem um papel muito importante dentro da comunidade onde está inserida, sendo para esta um referencial na construção coletiva de conhecimentos necessários para a qualificação da vida em todas as dimensões, a partir do diálogo de saberes com a comunidade.

\section{Agroecologia: produção de vida e alimentos saudáveis no campo}

O modelo do agronegócio tem gerado a alta concentração de terra, o êxodo rural, a dependência química e da genética, a mecanização e diminuição do trabalho vivo em suas áreas, e uma expressiva estratégia ideológica "O Agro é Pop, o agro é Tec, o agro é tudo" com o argumento de produção. E levou o Brasil a conquistar o título de maior consumidor de agrotóxico do mundo: "Em 2008, o Brasil ultrapassou os Estados Unidos e assumiu o posto de maior 
mercado mundial de agrotóxicos" (ABRASCO, 2012, p.15). Esse título é mantido e confirmado por Bombardi (2017). Sendo que toda a população é exposta aos agrotóxicos, por meio de consumo de alimentos e água contaminada. O seu uso tem gerado graves e diversificados danos à saúde provocados por estes venenos. E ainda sérios danos ao meio ambiente com a contaminação das águas, do ar, da chuva e do solo.

Desde o ano de 2016 estamos vivendo um crescente aumento na liberação do uso de agrotóxicos, que se intensificaram nos últimos dois anos. $E$ desde que o atual presidente chegou ao poder, 625 novos agrotóxicos foram liberados, com liberações de produtos altamente tóxicos e proibidos de serem utilizados pela União europeia.

Diante desse cenário devastador produzido pela agricultura capitalista, a Agroecologia se apresenta como uma estratégia de promoção da vida e da saúde. Um projeto da classe trabalhadora que propõe um projeto de campo articulado com um projeto de sociedade que é a favor da vida. Para produzir um campo com a redemocratização do acesso à terra, de sujeitos que tenham suas culturas e o modo de produzir que respeitem a natureza e o seu ciclo, que produza vida e alimentos saudáveis, com a participação dos jovens e das mulheres marca muito forte em construção da agroecologia.

A Agroecologia pensa a agricultura para produção de alimentos, "os alimentos são a base de sustentação da vida humana, toda ela em qualquer tempo" (CALDART, 2016, p.6). Quando falamos de alimento na Agroecologia estamos falando de alimentos saudáveis, que gere vida e saúde a quem se alimenta dele: "Uma agricultura em que especialmente os alimentos possam ser fonte de saúde, de alegria, de vida, como direito de todo ser humano" (CALDART, 2016, p.2). O alimento para a vida, que não só nutre de maneira saudável como forma de manter o funcionamento do nosso corpo, mas também na dimensão prazerosa de saborear, na dimensão espiritual com alimentos produzidos através de uma relação harmoniosa com a natureza e também na dimensão política, porque comer é um ato político, de comer um alimento vindo de uma produção onde o trabalho da juventude e das mulheres são valorizados, 
fortalecendo a agricultura camponesa e a construção da soberania alimentar, a partir de relações sociais justas e de trabalho digno e emancipado.

No Brasil, a Agroecologia é compreendida a partir de três dimensões: movimento, ciência e prática: "Assim sendo, podemos afirmar que a agroecologia, como a entendemos no Brasil, possui três dimensões: movimento, prática e ciência" (CARDOSO, 2019, p.139). Considerada um movimento de luta política contra o agronegócio, que representa a reprodução do capital no campo e como este se estabelece nesse espaço. Ela é prática, pois é a partir do histórico da práxis dos povos originários camponeses que ela se constrói e constrói seu conhecimento. E também é ciência no âmbito acadêmico através do conhecimento sistematizado, a partir do conhecimento e sabedoria popular, articulado ao conhecimento científico.

Portanto, a agroecologia é, desde sua origem, uma ciência contra-hegemônica, que procura não ignorar os saberes tradicionais em seus processos, pois, como ensinou Paulo Freire, o conhecimento deve ser construído a partir do diálogo com a população e do olhar sobre o que as pessoas fazem para solucionar seus problemas (CARDOSO, 2019, p. 139).

Marca importante na Agroecologia é o diálogo de saberes, pois diante da trama de conexões que esta propõe a partir de uma relação integradora com a natureza, com as culturas e com a humanidade esta se faz necessária.

E quem compreendia muito bem essa importância do diálogo de saberes era a engenheira agrônoma Ana Primavesi, a pioneira da Agroecologia no Brasil e na América Latina. Foi a primeira mulher a afirmar, num meio exclusivamente masculino, que o solo tem vida, e a propor a conciliação entre as leis da natureza e a agricultura. Além de sua importante contribuição para que a Agroecologia fosse pensada como uma ciência, ao mesmo tempo, considera um saber popular, que vem sendo praticado há séculos pelos camponeses.

Sempre que os manejos agrícolas são realizados conforme as características locais do ambiente, alterando-as o mínimo possível, o potencial natural dos solos é aproveitado. Por essa razão, a Agroecologia depende muito da sabedoria de cada agricultor desenvolvida a partir de suas experiências e observações locais (PRIMAVESI, 2008, p.9). 
A Agroecologia ver o agricultor como um experimentador, e a partir de suas experiências constroem o conhecimento na prática diária dentro dos seus agroecossistemas. Esses agroecossistemas possuem uma produção bastante diversificada de alimentos que garante a soberania alimentar dos povos, e a organização da agricultura a partir da Agroecologia, é imprescindível para a promoção da soberania alimentar. Uma síntese do conceito de "soberania alimentar" é apresentada por Stedile e Carvalho (2012):

Soberania alimentar é o conjunto de políticas públicas e sociais
que deve ser adotado por todas as nações, em seus povoados,
municípios, regiões e países, a fim de se garantir que sejam
produzidos os alimentos necessários para a sobrevivência da
população de cada local (p.715).

Fica compreendido que para ser soberano e assim protagonista do seu próprio destino o povo precisa ter condições, recursos e apoio para a produção dos seus próprios alimentos. A soberania alimentar e o conhecimento acumulado durante séculos, das gerações estão ameaçados, em meio à tanta negação de direitos e investidas sendo feitas contra à classe trabalhadora, sobretudo à do campo. Os povos camponeses estão cada vez mais reféns das grandes empresas, com a manipulação das sementes, sendo negado a eles o direito da multiplicação das sementes. "As sementes são o berço da biodiversidade e devem estar sob o domínio dos camponeses (as)" (CARDOSO, 2019, p.142).

Caporal e Petersen (2012) afirmam que uma das características marcantes da Agroecologia no Brasil é um vínculo com a defesa da agricultura familiar camponesa, enquanto base social de estilos sustentáveis de desenvolvimento rural: Uma característica marcante do Agroecologia no Brasil é seu vínculo inextrincável com a defesa da agricultura familiar camponesa como base social de estilos sustentáveis de desenvolvimento rural (CAPORAL \& PETERSEN, 2012, p.66).

Os princípios agroecológicos estão presentes ainda que limitadamente na agricultura camponesa e esta é imprescindível na Educação do Campo, pois foi criada pelos sujeitos que a fazem. Assim a agroecologia deve permear a educação do campo propondo um novo modelo de desenvolvimento do campo, 
nas suas diversas dimensões, cumprindo o compromisso da educação do campo com esse povo que trabalham e vivem no campo.

\section{Juventudes do Campo}

No Brasil temos 51,3 milhões de jovens, destes 8,6 milhões são jovens camponeses, segundo levantamento realizado pelo último censo do IBGE, em 2010. Este número expressivo da juventude camponesa que corresponde a quase $1 / 3$ da população que vive hoje no campo, tem um papel muito significativo como força de trabalho, na garantia da soberania alimentar, na conservação do nosso patrimônio material e imaterial do campo, na continuidade da luta dos trabalhadores rurais e na permanência do território camponês. Estes jovens representam uma diversidade de formas de reprodução da vida no campo, que se dá em diversos cantos do nosso país, e que é invisibilizada enquanto sujeitos sociais.

De acordo com o Estatuto da Juventude, Lei $n^{\circ} 12.852$, são consideradas jovens as pessoas com idade entre 15 (quinze) e 29 (vinte e nove) anos de idade. Para a Organização das Nações Unidas para a Educação, a Ciência e a Cultura - UNESCO e a Organização Mundial da Saúde - OMS a faixa etária de 15 a 24 anos de idade é utilizada para classificar a população jovem. Porém, há uma extensa discussão em torno do conceito de juventude e da definição do grupo etário classificado como jovem, não existindo um consenso para a definição sobre juventude.

Essa juventude de que estamos falando não é homogênea, diferentes condições de vida e trabalho produziram diferentes situações juvenis no campo: os jovens agricultores familiares, os jovens assalariados rurais, os jovens quilombolas, os jovens extrativistas, os jovens pescadores e os jovens indígenas. Os processos de socialização nos quais os jovens estão inseridos produz a especificidade da juventude, formando categorias juvenis diversas no campo e assim se percebe que, não existe uma juventude, mais sim, juventudes rurais:

Este posicionamento, categorizar os jovens por sua socialização principal, rompe com as definições de caráter substancialista sobre a juventude, possibilitando construir a categoria analítica 
de modo relacional, isto é, em termos de sua posição num espaço de relações sociais. Com efeito, a reconstrução sociológica da situação juvenil, com base no processo de socialização, confere maior coerência à proposta de privilegiar as noções de juventudes e jovens no plural (WEISHEIMER, 2013, p. 26).

Para reconhecer essa diversidade das populações do campo, das águas e das florestas, é preciso olhar para esse espaço de uma forma bastante heterogênea, não só buscando identificá-la mas reconhecer de fato as formas de vida, de luta, de organização camponesa e as diferentes formas de participação social que constroem esse sujeito.

Quando voltamos o nosso olhar para o debate acerca da Juventude Camponesa, dois problemas chamam a atenção dos pesquisadores deste segmento, a migração e a invisibilidade da juventude rural, como constatou Weisheimer (2013):

Primeiro, as estatísticas dos processos migratórios demonstraram que o êxodo rural, nas últimas décadas, foi protagonizado principalmente por jovens, entre os quais as mulheres constituíram a maioria. Tal fenômeno contribuiu para um acentuado processo de envelhecimento e masculinização das populações rurais. Outro aspecto, menos explícito, porém não menos importante, tem sido a persistência de uma certa situação de invisibilidade social a que estão submetidos os jovens no meio rural (WEISHEIMER, 2013, p.22).

Além do predomínio juvenil nesse movimento migratório, outra característica importante apresentada é a participação em maior número de jovens do sexo feminino. Esse fenômeno tem gerado o envelhecimento e a masculinização das populações no campo, agravando ainda mais o problema da continuidade do campo por populações jovens, sendo que estes homens não conseguirão gerar descendentes para o sucederem na propriedade da família. Evidenciando assim a importância do papel da sucessão geracional para a continuidade do campo, sendo esta permanência garantida pela passagem a um dos filhos da administração da propriedade familiar:

A continuidade da profissão agrícola depende da reprodução social com base familiar, isso porque a sucessão tende a ser endógena, com pelo menos um filho sucedendo o pai na administração da unidade produtiva, sendo pouco freqüente a 
adesão a essa atividade por pessoas sem vivência familiar nesse ramo (WEISHEIMER, 2005, p. 27).

A sucessão nas unidades familiares é de extrema importância para a continuidade do campo e a reprodução do modo de vida camponês. O intenso movimento migratório de saída dos jovens do campo terá como consequência milhares de propriedades que não terão sucessão, serão vendidas, ou até mesmo abandonadas. Os jovens agricultores familiares tem um papel estratégico para o desenvolvimento do campo e o fortalecimento da agricultura familiar. Isso reforça a importância deste tema para a Educação do Campo, diante de tantas lutas para garantir o seu território e uma educação que atenda às suas especificidades.

Somado a esses fatores existe ainda a invisibilidade desses sujeitos dentro dos seus espaços de vivência e atuação, não gozando do direito de participar das decisões que impactam na sua vida e no seu futuro.

Trata-se, portanto, de uma ação social que implica em não ver o outro, não enxergar sua existência social e tudo que decorre deste fato. Ou seja, por invisibilidade social entendemos todo um processo de não reconhecimento e indiferença em relação a sujeitos subalternos da sociedade. Esta invisibilidade social nega ao outro o direito ao reconhecimento e à identidade social (WEISHEIMER, 2013, p.23).

Isso significa que esses sujeitos estão imperceptíveis em suas relações sociais, não sendo reconhecidos nos seus espaços e suas demandas estarão fora do bojo das discussões, negando a estes o direito de ser reconhecido e também à sua identidade. Este segmento enfrenta a falta de confiança e autonomia dentro das próprias famílias, estas relações sociais são marcadas pela hierarquia e autoridade, principalmente com relação ao sexo feminino, onde o mecanismo de controle e vigilância é ainda maior:

O peso da autoridade paterna no espaço doméstico é reproduzido nas relações de trabalho familiar e na organização do lote. Essa autoridade cria mecanismos de vigilância e controle sobre os jovens através das relações familiares e demais redes sociais, principalmente mulheres, que se estendem para os espaços que frequentam (CASTRO, 2009, p. 193). 
Esse comportamento também é observado em espaços coletivos, não permitindo a participação dos jovens nas tomadas de decisões:

Os relatos dos jovens sobre suas participações em reuniões foram marcados pela desqualificação das suas intervenções pelos adultos. São exemplos falas que expressam a falta de espaço para se participar das decisões no âmbito familiar, como: "Ele [pai] não ouve ninguém. " $E$ falas que se referem aos espaços de organização de assentamentos e acampamentos, como "Ninguém ouve os jovens". Mesmo jovens lideranças de movimentos sociais reconhecidos nacionalmente afirmaram vivenciar essa relação de subordinação tanto no espaço doméstico, quanto nos espaços de organização (CASTRO, 2009, p.194).

Essa condição de subordinação tem tirado a autonomia e o direito a voz desses jovens de participação política nos espaços onde atuam e na propriedade da família. A renda gerada na propriedade com a participação da sua força de trabalho também não chega até o jovem, e o trabalho das jovens é desvalorizado e são direcionadas ao trabalho doméstico que não gera renda.

Weisheimer (2013), apresenta a juventude rural como um segmento altamente fragilizado de nossa sociedade, invisíveis ao meio acadêmico e ao sistema político, aos quais tem sido negado o acesso ao conjunto de direitos básicos para a constituição de um cidadão, e sendo estes não reconhecidos socialmente como sujeitos de direitos dificilmente conseguiram se tornar pauta nas agendas governamentais:

Entre todos os excluídos e marginalizados de nossa sociedade atual, os jovens que vivem em territórios rurais figuram entre os mais vulneráveis. A invisibilidade social a que estes jovens estão submetidos consiste numa das expressões mais cruéis de exclusão social, uma vez que, dessa forma, eles não se tornam sujeitos de direitos sociais ou alvos de políticas públicas, inviabilizando o rompimento da própria condição de exclusão (WEISHEIMER, 2013, p.23).

A superação dessa invisibilidade social da juventude rural se dará a partir do reconhecimento das diferenças dentro dessa categoria, contribuindo para a não perpetuação da invisibilidade desta riqueza de modos de vida, e diferentes processos de socialização no campo que produzem diversas categorias juvenis que precisam ser reconhecidas nas suas especificidades. "Superar a invisibilidade das juventudes rurais implica em reconhecer que ela não é 
simplesmente um elemento da diversidade, mas que contém, ela mesma, toda uma diversidade de tipos sociais" (WEISHEIMER, 2013, p. 26). Nesse contexto de violenta desumanização, estes jovens têm se posicionado: "Apesar de toda essa exclusão a que estão submetidos, estes não desanimam, contudo, esta exclusão é confrontada por manifestações de organizações de juventude rural, cada vez mais presentes no cenário nacional" (CASTRO, 2009, p.195).

Estes jovens, diante desse cenário, têm se constituído em atores políticos e organizados em movimentos sociais do campo de diversas ordens tem reafirmado a sua identidade e as suas bandeiras de lutas:

Esse jovem rural se apresenta longe do isolamento, dialoga com o mundo globalizado e reafirma sua identidade como trabalhador, camponês, agricultor familiar, acionando diversas estratégias de disputa por terra e por seus direitos como trabalhadores e cidadãos (CASTRO, 2009, p.183).

Com um número cada vez mais expressivo de eventos e organizações juvenis, que configurou o campo político da juventude, esta juventude organizada politicamente tem pressionado no campo das políticas públicas, mas não só como público-alvo, querem ser também propositores dessas políticas:

Assim, a partir dos anos 2000, observamos uma presença importante no cenário político nacional: a juventude como categoria de identificação política. Nesses 15 anos, podemos afirmar que se configura um campo político da juventude. (CASTRO, 2011, apud CASTRO, 2016, p. 194).

A promulgação do Estatuto da Juventude (Lei $n^{\circ}$ 12.852) em agosto de 2013, principal marco legal das políticas e direitos da juventude brasileira, é outro marco importante para reconhecimento da juventude como sujeito de direitos. Outro passo decisivo foi o Plano Nacional de Juventude e Sucessão Rural (2016), que teve como objetivo integrar e articular políticas, programas e ações para a promoção da sucessão rural e a garantia dos direitos da juventude do campo e afirma a centralidade do papel do Estado na condução dessas ações.

É importante destacar a visibilidade que ganha a diversidade da juventude do campo, das águas e das florestas, que ganham identidade política nos movimentos sociais rurais e passam a ser representadas e demandarem suas questões específicas. Porém, apesar de tantas conquistas, uma parcela ainda 
muito grande da população jovem no campo ainda convive com a falta de autonomia e de escolha quanto a ficar ou sair do campo, pois sem a educação no campo, o acesso à terra e a créditos rurais não conseguiram construir sua autonomia:

Para muitos jovens, viver no mundo rural, hoje, ainda significa enfrentar barreiras para sua autonomia e suas possibilidades de escolha. Ou seja, as possibilidades reais de escolarização, acesso à terra e à renda, muito valorizados como caminhos para a construção de autonomia, não estão ao alcance de muitos, mesmo após 14 anos dos governos Lula-Dilma. Apesar dos esforços empreendidos nesse período, muitas dessas demandas não foram atendidas (CASTRO, 2016, p.200).

Não podemos mais falar em fixar os jovens no campo, mas sim de criar condições para que os jovens que querem permanecer permaneçam com a oferta de serviços públicos, condições de moradia, de mobilidade, de geração de renda, de construir a família em um ambiente saudável, criando assim condição de vida no campo e cidadania. $E$ assim, convivemos com as fragilidades na materialização dessas conquistas, com a falta de políticas permanentes não tendo se concretizado enquanto política de Estado.

As juventudes do campo, das águas e das florestas tem se constituído enquanto sujeitos políticos, e nos últimos 15 anos, organizados em movimentos sociais tem forjado uma luta para garantir as condições de permanência no seu território, com qualidade de vida e cidadania:

Existe uma geração de jovens organizados nos movimentos sociais sindicais, extrativistas, camponeses, indígenas, quilombolas, ribeirinhos e pescadores que luta pela permanência da juventude de uma forma articulada com a mobilização por um desenvolvimento rural justo, inclusivo e sustentável, social e ambientalmente (CASTRO et.al., 2017, p.295).

A permanência dessas juventudes no campo, pode significar a garantia da segurança alimentar do nosso país, a continuidade da agricultura familiar, a conservação do patrimônio cultural e tradições nas comunidades camponesas, indígenas e tradicionais.

A agricultura familiar é quem alimenta a população brasileira, e ela tem disputado a produção de alimento de forma agroecológica. Segundo Castro et.al. 
(2017), a produção de alimentos no Brasil depende fortemente da agricultura familiar camponesa, sendo esta responsável pela maior parte da produção de mandioca, feijões, leite de vaca, suínos e por parte importante da produção de milho, arroz, café, trigo e ovos que são consumidos pelas famílias brasileiras.

E o jovem é a possibilidade de reprodução desse modelo que produz alimento saudáveis, que tem uma relação com a natureza, que conserva os recursos naturais. Este modelo que traz o conhecimento da agricultura familiar camponesa e das comunidades tradicionais e indígenas. E a continuidade dessa missão pelos jovens é que vai garantir a segurança alimentar do nosso país: " Termos gerações se sucedendo nessa missão é central para garantirmos a segurança alimentar que o Brasil vem conquistando" (CASTRO et.al., 2017, p.297).

E assim a Agroecologia tem se tornado agenda prioritária para as juventudes, ao lado de temas bastante relevantes como a terra e a Educação do Campo: "É nesse contexto que a agroecologia e a produção orgânica também se tornam visíveis como agenda prioritária da juventude, ao lado da educação do campo, da geração de renda e do acesso à terra" (CASTRO et. al. 2017, p.295). Assim, esse segmento nos diversos espaços de participação social e política tem pautado a Agroecologia como modelo de desenvolvimento rural sustentável do seu território: "Pode-se afirmar que a juventude aparece como um segmento que abraçou a agenda da agroecologia como central nas suas pautas de reivindicação" (CASTRO et.al., 2017, p.302).

E diante da crise ambiental instalada pelo capitalismo voraz que demanda cada vez mais recursos e terras, só é possível pensar na continuidade de vida no campo a partir dessas duas categorias, juventude e agroecologia. Contudo, para ter essas categorias presentes no campo, que garantirão a continuidade da vida, da produção de alimentos saudáveis e do território camponês, se faz necessária a reforma agrária e uma política agrícola centrada na agricultura camponesa com base agroecológica e na juventude, e a garantia das condições ampliadas de vida para que o jovem permaneça no campo, se assim o quiser.

\section{Considerações finais}


A juventude é indispensável para a continuidade do território camponês e a garantia da nossa segurança alimentar, diante da constante ameaça deste território pelo avanço do agronegócio demandando cada vez mais terra para produção de comoditties agrícolas, ou seja, produção de mercadoria e não de alimento. A continuidade da luta dos trabalhadores rurais também é materializada no jovem camponês. $E$ assim, entendendo a importância da continuidade da luta e da permanência do território camponês, na perspectiva do campo enquanto espaço de vida, com comunidades, com a produção de alimentos saudáveis, com relações sociais humanas e justas, enquanto produtor de cultura e com dignidade e justiça social, é imprescindível a formação em Agroecologia para a Juventude Camponesa nos espaços escolares e não escolares, diante da importância política, social, cultural e econômica deste tema para a construção de um campo mais digno, feliz e com sustentabilidade da vida.

Esta Pesquisa fomentou a construção de uma proposta de Formação em Agroecologia com a Juventude Camponesa em Amargosa-BA. Esta proposta foi fundamentada nos princípios da Educação do Campo e da Agroecologia, tendo a pesquisa e o trabalho como princípio educativo, partindo da realidade desses estudantes e centrada na dialética para construção do conhecimento agroecológico.

Nesta formação que iniciamos, utilizamos um questionário diagnóstico com a turma para fazermos um levantamento inicial dos conhecimentos trazidos pelos estudantes e avaliarmos o quanto esta formação irá contribuir com o processo emancipatório social e humano dos sujeitos envolvidos. O Inventário da Realidade foi utilizado como instrumento de pesquisa para levantar e registrar de forma organizada os dados da realidade das comunidades onde estavam inseridos estes estudantes, e para garantir os registros e a memória do processo vivido eles tinham um diário coletivo de campo. Todo os dados levantados nas comunidades inventariadas foram socializados e discutidos com a turma. A partir das problemáticas identificadas, os estudantes se posicionaram apresentando propostas de ações para transformar essa realidade. Assim, esta formação contribuiu com o processo emancipatório desses estudantes que a partir de uma 
postura crítica e reflexiva fazem a leitura da sua realidade e produzem um conhecimento para transformação desta.

Neste contexto, a Agroecologia se apresenta de forma imprescindível na construção de um novo projeto para o campo brasileiro, onde se pretende a superação desse modelo econômico e agrícola que promove a insustentabilidade da vida no campo. E isso só será possível a partir da inserção desta importante temática nas escolas do campo e nos espaços não escolares de formação. Neste sentido, é necessário iniciar essa discussão imediatamente nestes espaços, tendo como objetivo o fortalecimento das escolas do campo, sendo estes espaços de luta e resistência dos povos.

\section{Referências}

Juventude rural, do campo, das águas e das florestas: a primeira geração jovem dos movimentos sociais no Brasil e sua incidência nas políticas públicas de juventude. Revista de Ciências Sociais, $n^{\circ} 45$, Julho/Dezembro de 2016.

Desidades, $\mathrm{n}^{\circ} 1$, ano 1, Dezembro de 2013.

Sobre a invisibilidade social das juventudes rurais. Revista Acesso em: julho/19.

ALVES, A. J. O planejamento de pesquisas qualitativas em Educação. Faculdade de Educação-UFRJ. Cad. Pesq., São Paulo, maio 1991, p.53-61.

ARROYO, M. G. Currículo, território em disputa. Petrópolis: Vozes, 2011.

BOMBARDI, L. M. Geografia do uso de agrotóxicos no Brasil e conexões com a União Europeia. São Paulo: FFLCH-USP, 2017.

BRASIL. Ministério da Educação. Cadernos Secad 2. Educação do Campo: diferenças mudando paradigmas. Brasília, 2007.

BRASIL. Política Nacional de Educação na Reforma Agrária (Decreto n 7. 352, 04/11/2010).

CALDART, R. S. Caminhos para transformação da escola: trabalho, agroecologia e estudos nas escolas do campo. $1^{\text {a }}$ ed. São Paulo: Expressão Popular, 2017.

CALDART, R. S. Escolas do Campo e Agroecologia: uma agenda de trabalho com a vida e pela vida! Porto Alegre, fev 2016. Disponível em:< https://www.unioeste.br/portal/arq/files/GEFHEMP/01Escolas do Campo e Ag roecologia.pdf>. Acesso em: 01 julho de 2019. 
CALDART, R. S. Pedagogia do Movimento Sem Terra. $4^{a}$ ed. São Paulo: Expressão Popular, 2012.

CALDART, R. S. Por uma educação do campo: traços de uma identidade em construção. In: ARROYO, M., CALDART, R. S. e MOLINA. M. C. (Orgs). Por uma Educação do Campo. 5a ed. Petrópolis, RJ: Vozes, 2011.

CAPORAL, F.R.; PETERSEN, P. Agroecologia e políticas públicas na América Latina: o caso do Brasil. Agroecología. v.6, 2012, p.63-74.

CARDOSO, I. M. A questão agrária, agroecologia e soberania alimentar. In: MOLINA, M. C.; MARTINS, M. de F. A.(orgs.). Formação de formadores: reflexões sobre as experiências da licenciatura em educação do campo no Brasil. 1. ed. Belo Horizonte, MG : Autêntica Editora, 2019.

CARNEIRO, F F; PIGNATI, W; RIGOTTO, R M; AUGUSTO, L G S. RIZOLLO, A; MULLER, N M; ALEXANDRE, V P.; FRIEDRICH, K; MELLO, M S C. Dossiê ABRASCO - Um alerta sobre os impactos dos agrotóxicos na saúde. ABRASCO, Rio de Janeiro, abril de 2012. $1^{\text {a }}$ Parte.

CASTRO, E. G. Juventude rural no Brasil: processos de exclusão e a construção de um ator político. Revista Latinoamericana de Ciencias Sociales, Niñez y Juventud, Vol. 7, $\mathrm{n}^{\circ}$. 1, jan-jun 2009).

CASTRO, E. G., FERREIRA, A. T., SERRADOURADA, R. N., CARVALHO, E. Juventude e Agroecologia: a construção de uma agenda política e a experiência de Planapo. In: SAMBUICHI, R. H. R. et al (org.). A política nacional de agroecologia e produção orgânica no Brasil: uma trajetória de luta pelo desenvolvimento rural sustentável- Brasília: Ipea, 2017.

CASTRO, E. V. ."No Brasil, todo mundo é índio, exceto quem não é”, Entrevista à equipe de edição, originalmente publicada no livro Povos Indígenas no Brasil disponível

em 2001/200https://pib.socioambiental.org/files/file/PIB.../No_Brasil_todo_mundo_é _índio.pdf

FERNANDES, B. M. \& MOLINA, M. C. O campo da educação do campo. 2005. Disponível em: http://www2.fct.unesp.br/nera/publicacoes/ArtigoMonicaBernardoEC5.pdf

FERNANDES, B.M.; CERIOLI, P. R.; CALDART, R. S. Primeira Conferência Nacional "Por Uma Educação Básica do Campo": texto preparatório. In: ARROYO, Miguel, CALDART, Roseli S. e MOLINA, Mônica C. (Orgs). Por uma Educação do Campo. 5a Ed. Petrópolis, RJ: Vozes, 2011.

FERNANDES, M. Os campos da pesquisa em Educação do Campo: espaço e território como categorias essenciais. In: Molina, M. C. (org.). Educação do Campo e pesquisa: questões para reflexão. Brasília: MDA, 2006.

FREIRE, P. Pedagogia do oprimido. 50. ed. Rio de Janeiro: Paz e Terra, 2011. 
IBGE - INSTITUTO BRASILEIRO DE GEOGRAFIA E ESTATÍSTICA. Censo Demográfico 2010. Educação e deslocamento. Resultados do universo. Rio de Janeiro: IBGE, 2010b. Disponível em: http://www.ibge.gov.br .

LUDKE, M. ; ANDRE; M. Pesquisa em educação: abordagens qualitativas. São Paulo:EPU, 1986.

MOLINA, Mônica Castagna (Org.). Educação do Campo e Pesquisa II: questões para reflexão. Brasília, MDA/MEC, 2010.

PISTRAK, M. M. Fundamentos da escola do trabalho. $3^{a}$ ed. São Paulo: Expressão Popular, 2011.

PRIMAVESI, A. M. Agroecologia e manejo do solo. Revista Agriculturas, volume $5, n^{\circ} 3$, Setembro de 2008.

SANTOS, C.E.F.; PALUDO, C. ; OLIVEIRA, R.B.C. Concepção de Educação do Campo. In: UFBA. Universidade Federal da Bahia. Cadernos didáticos sobre educação no campo. Org: TAFFAREL, Celi Nelza Zülke; et all. - Salvador: EDITORA, 2010.

SAUER, S. Reflexões esparsas sobre a questão Agrária e a demanda por terra no Século XXI. In: A Questão Agrária no Brasil. Debate sobre a situação e perspectivas da reforma agrária na década de 2000. João Pedro Stedile (org.); Douglas Estevam (assistente de pesquisa). 1. ed.- São Paulo: Expressão Popular, 2013.

SILVA, Maria do Socorro. Educação do Campo e Desenvolvimento: uma relação construída ao longo da história, 2004. http://www.forumeja.org.br/ec/files/Texto\%20Base\%20Educa\%C3\%A7\%C3\%A 3o\%20do\%20Campo.pdf Acesso em 30/04/2011.

STEDILE, J. P \& CARVALHO, H. M. Soberania Alimentar. In: CALDART, R., PEREIRA, I. B., ALETEJANO, P., FRIGOTTO, G. (ORGS). Dicionário de Educação do Campo. Rio de Janeiro, São Paulo: Escola Politécnica de Saúde Joaquim Venâncio, Expressão Popular, 2012.

WEISHEIMER, N. Juventudes rurais: mapas de estudos recentes. Brasília: MDA, 2005.

\section{Sobre os Autores}

\section{Lílian Souza Conceição Santos}

lilianscon@hotmail.com

Mestre em Educação do Campo (2020) e Especialista em Educação no Campo e Desenvolvimento Territorial do Semiárido Brasileiro pela Universidade Federal do Recôncavo da Bahia (2014). Licenciada em Biologia pela Universidade Federal da Bahia (2007). Atua como professora de Biologia da Rede Estadual de Ensino da Bahia. 


\section{Rosineide Pereira Mubarack Garcia}

rose.mubarack@ufrb.edu.br

Doutora em Educação/UFBA (2008), Mestre em Ensino, Filosofia e História das Ciências/UFBA (2004), Especialista em Psicopedagogia aplicada ao Desenvolvimento de Recursos Humanos/CEPOM (1997) e Pedagoga/FEBA (1995). Professora Associada da Universidade Federal do Recôncavo da Bahia (UFRB), docente do Programa de Pós-Graduação em Educação do Campo (CFP/UFRB) e do Programa de Pós-graduação em Gestão de Políticas Públicas e Segurança Social (CCAAB/UFRB) e Licenciatura em Biologia (CCAAB/UFRB). 